\title{
Research on the Green Manufacturing System and Its Structure
}

\author{
Ping Tao and Gang Zhao* \\ College of Machinery and Automation, Wuhan University of Science and Technology, Wuhan, Hubei \\ 430081 \\ snowcampus@163.com
}

Keywords: Green manufacturing; Systemic engineering; Systemic structure; Spatial dimension; Time dimension

\begin{abstract}
Supported by the theory of comprehensive integration system, the integrated model of systemic engineering of green manufacturing is built in the perspective of systemic engineering with the concept and connotation of green manufacturing, fully describe the structure and composition of green manufacturing system from the perspective of system, the overall structure of the green manufacturing system model is constructed. The composition of green manufacturing system are discussed from the space dimension, the time dimension and multiple view, the contributions achieved in this article have laid a foundation for the development of the science of green manufacturing.
\end{abstract}

\section{Introduction}

Green manufacturing is also known as Environmentally Conscious Manufacturing (ECM) or Manufacturing for the Environment (ME). It is a modern manufacturing mode taking comprehensive account of environmental impact and resource consumption, which aims to making minimum negative impacts on the environment and attaining higher resource utilization in whole life cycle of the production design, manufacture, packaging, transportation and reuse. The implement and optimization for the green manufacturing help the enterprise earns more economic benefits and social benefits.

In recent years, scholars have made some researches on green manufacturing system. Liu Fey, Zhang Hua, etc. proposed the new concept of "green integrated manufacturing system" on the basis of a series of integration characteristics of green manufacturing [1]. Zhang Hua discussed the system structure of green manufacturing system, including the whole process with two levels of control, three specific content and two goals [2]. According to the theory of green manufacturing, Liu Gangue put forward a model of green manufacturing system [2], which is generalized as three contents, three ways and two goals and builds the research framework of green manufacturing system in the enterprises. Li Jian, etc. examined the manufacturing system oriented to circular economy within three principles: the reduction, reuse and recycle. He also put forward the circular economy under the mode of the manufacturing system focused on three key levels: enterprise production level, the symbiotic level and social consumption level [3]. Zheng Jiliang discussed the green integrated manufacturing system from multi-perspectives, such as the theory of green manufacturing, advanced manufacturing system, the circular economy, etc.

Green manufacturing is a new manufacturing mode and in the continuous development, so far there is no clear definition for green manufacturing system and lack of comprehensive, multiple points of view in-depth research. Thus, how to fully describe the structure and composition of green manufacturing system from the perspective of system, based on the definition and connotation of green manufacturing system, is of great significance to the study of green manufacturing system. 


\section{The Concept and Connotation of Green Manufacturing System}

As the green manufacturing system research history is short, the concept and the connotation is still in the exploratory stage, so far no clear definition. According to the concept of "green manufacturing" and the definition of "system" in system theory and comprehensive literature views of research scholars, we give a green manufacturing system are defined as follows:

Green manufacturing system is the whole process of product life cycle and involved in manufacturing resource elements and the environmental impact of the green characteristics of an organic whole. The manufacturing resource elements include resources (material, energy, equipment, etc.), capital, human resources and the related theory of green manufacturing, green manufacturing technology and manufacturing information. The environmental impact factors refer to the ecological impact, resource utilization, occupational health, safety and a series of general environmental impact factors. The green characteristic refers to the minimum negative impact to the environment during the whole process of the product life cycle, the highest utilization rate of resources.

From the definition of green manufacturing system, the main connotations of green manufacturing system are as follows:

1) The green manufacturing system is a whole life cycle of product process, and considering the environmental impact and resource consumption of modern manufacturing system, the goal is to minimize impact on the environment and make optimal resource utilization of the products in the entire product life cycle from the design, manufacture, packaging, transportation and use to disposal.

2) The pursuit of green manufacturing system is not only to achieve the economic benefits of system, more emphasis on sustainable development and environmental benefits. The operation and development of green manufacturing system must satisfy the sustainable development strategy of "three measurements"—which are development level, harmony degree, and sustaining ability. Its system of decision-making is a multi-objective decision making, namely time $\mathrm{T}$, quality $\mathrm{Q}$, cost $\mathrm{C}$ and E R, resource consumption, environmental impact in order to realize the global optimization of system.

3) The green manufacturing system is a closed loop of composite system, which contains the raw materials, industrial production, product usage, scrap-multiple remanufacturing, recycling. It is currently focusing on product whole life cycle and will be further development to the circulation use of the extension of the life cycle for many times in the future.

4) The green manufacturing system is a highly integrated manufacturing system. It includes problem field of integration, integration, social integration and information integration, etc. From the problem of integration: green manufacturing system is a mature manufacturing problems, environmental protection and resource optimization utilization of complex manufacturing system; from the domain integration, green manufacturing system involves the manufacturing system, natural ecological environment, natural resources, consumer service system, and many other problems in the field of system; at the same time, the scope of the green manufacturing system is very broad, including mechanical, electronic, food, chemical industry, military industry, etc., covering almost the entire industrial sector.

5) The elements of green manufacturing system are more abundant. .Elements within the green manufacturing system include not only traditional elements in the manufacturing system, but also the entire product life cycle process of natural ecological environment system and the influential factors such as natural resources system, that the product whole life cycle of resource consumption and environmental impact factors become the important elements of green manufacturing system.

\section{The Overall Structure and Composition of Green Manufacturing System}

Green manufacturing system possesses the structure characteristics of multidimensional, multi-view, multi-fluid movement, as shown in Fig. 1 below as three-dimensional structure model of green manufacturing system. From the space dimension, the green manufacturing system is from low to 
high levels of the structural characteristics of hierarchical system; from the time dimension, the green manufacturing system is a manufacturing system based on the lifecycle of the product cycle. From the product dimension, the green manufacturing system will continuously enter manufacturing resources for processing and manufacturing into green products; it presents the structure characteristics of multiple view and always with the material flow, energy flow and environmental flow and the flow of information flow in the operation of green manufacturing system.

The Structure Characteristics of Green Manufacturing System Based on Multiple Views. Green manufacturing system belongs to the manufacturing system with architecture characteristics of multiple views of the manufacturing system, such as the process view, functional view, organization view, resource view, information view, etc. However, the function of the green manufacturing system is to maximize economic and sustainable development coordination, the goal is to make minimum negative impact to the environment and attain higher resource utilization in the whole life cycle of the production design, manufacture, packaging, transportation and use to disposal as well as realize coordinated optimization of the enterprise economic benefit and social benefit. Thus, green manufacturing system not only talk about its system structure characteristics from the perspective of manufacturing, but also from the aspects of resource utilization, environmental impact; while resources and the environment not only exists in the manufacturing process, it also exists in the whole product life cycle. In line with the above consideration, to underline the importance of resources and environment in the architecture of system, we present the structure characteristics of multi-view green manufacturing system on account of production whole life cycle process, as shown in Fig. 2 below.

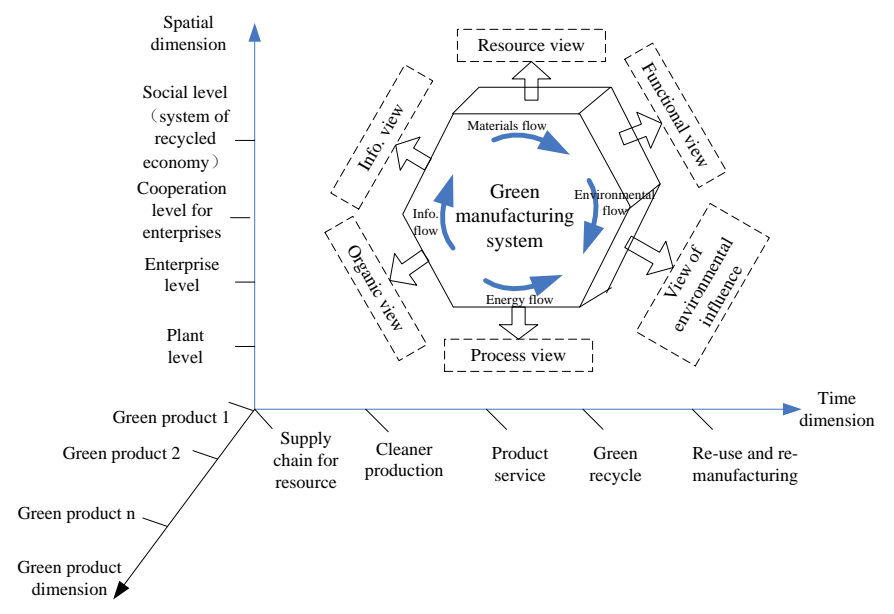

Figure 1. 3D organic model of the green manufacturing system

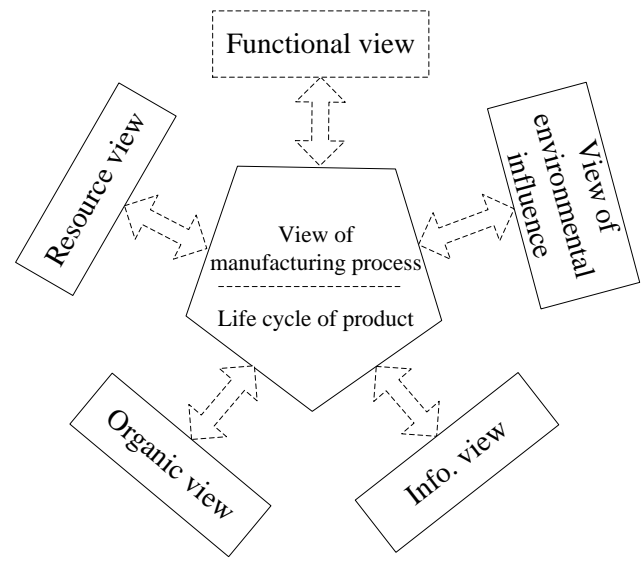

Figure 2. Multiple views of the green manufacturing system

His view of manufacturing process is in the central position of the system structure. It builds the organic connection between five other views and come into operation basis on the production whole life cycle process, respectively from the function, resource utilization, environmental impact, organization structure, information and other different emphasis to describe the composition of green manufacturing system. All of the views compose an organic whole, which can be used as a general view of the green manufacturing system. In the specific research, according to the different emphasis of description, can be added and trade-offs. 
The Composition of Green Manufacturing System Based on Spatial Dimension. From the space dimension, in order to reach the goal of optimal utilization of resources, the system must constantly integrate from low to high levels of green manufacturing system of green manufacturing system, each higher level is the integration development of low level, high level integration not only possesses similarity with lower levels, but also have stronger ability to adapt to strain the constraints of resources and environment. Based on spatial dimension system structure of green manufacturing system, the multi-level framework is shown in Fig. 3.

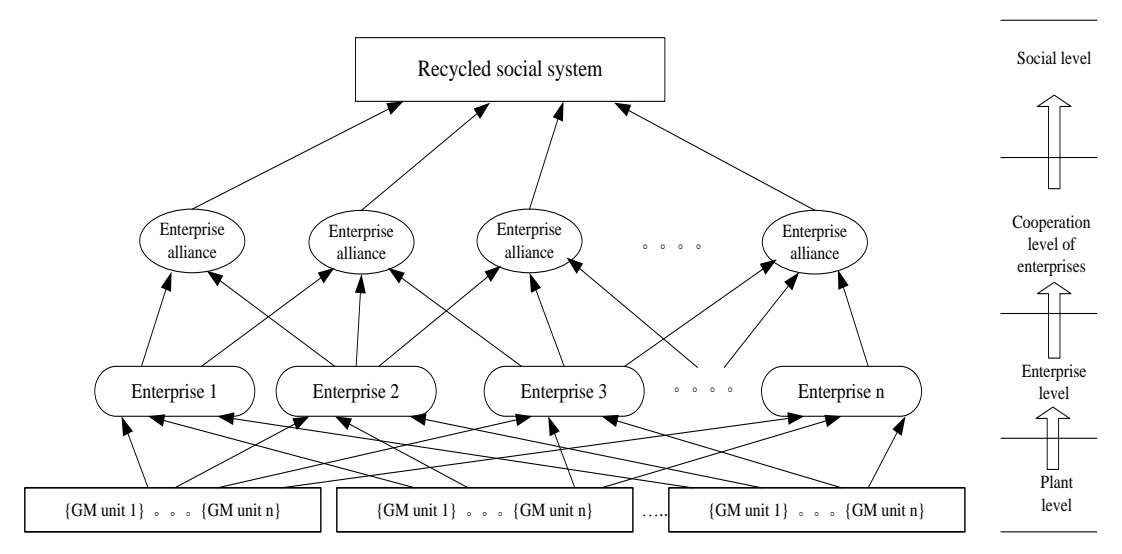

Figure 3. The hierarchical framework of the green manufacturing system

Green equipment unit, green process unit, green manufacturing technology unit and green assembly unit constitute the basic elements of the system. We are here to call them collectively as the green manufacturing unit. The combination of the green manufacturing units constitutes the lowest layer of green manufacturing system: the shop floor. Multiple workshop layers construct the system of green manufacturing of enterprise level. As the constraints of system resources and environment intensify, green manufacturing is not just limited to the enterprises. It will look for the resources optimization, recycling utilization in a great range of areas. By imitating the nature ecological system operation mode, synergy and symbiotic relationship are formed between enterprises to realize green strategy alliance on enterprises collaboration level. With the integration development of green manufacturing system unceasingly, it will eventually appear integration trend among industrial system, social system and the ecological environment system, form a green integrated manufacturing system on social level---circular social system.

The Composition of Green Manufacturing System Based on Time Dimension. Based on time dimension, the operation of the green manufacturing system can be seen as based on product whole life cycle of product design and management, procurement and supply of resources, clean production process, product use, product recycling, and reuse and remanufacturing, organic combination of each link. Each link exists between the complex material flow, energy flow and environmental flow, the flow of information flow.

According to green manufacturing theory and the relevant researches on the green manufacturing system, we draw a construction graph of green manufacturing on the whole life cycle of product process, as shown in Fig. 4. 


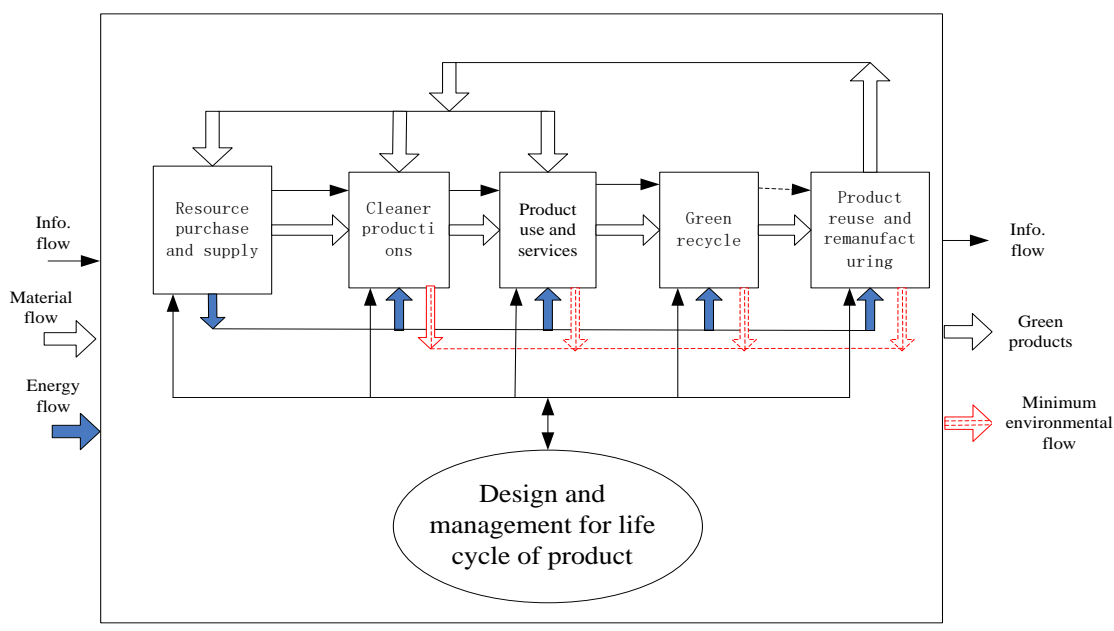

Figure 4. Construction graph of green manufacturing on the whole life cycle of product process

The design of the system is mainly composed of product life cycle and management, procurement and supply of resources, clean production, the product use and service, green recovery, recycling and remanufacturing of six subsystems.

(1) the design and management of product life cycle, including green design and information management, product life cycle, from the Angle of the design is not limited to the design of the product itself, also includes the resources of the whole process of product life cycle (soft and hard resources) procurement plan design, product design, the clean production of after-sales service plan design, product design, product recycling of remanufacturing scheme design, etc.; from the Angle of information management, it covers from product market demand, product design, processing and manufacturing, product after-sales service, until the product recovery remanufacture, etc. The whole process of management, with the aid of cloud manufacturing, forms a multi-level collaboration.

(2)Procurement and supply: the resources on the cloud manufacturing service platform to build resource logistics procurement and supply system, through the green supply chain make full use of the system or other system resources available (such as the waste systems or other systems), as far as possible to reduce the consumption of natural resources. Its key part is the green manufacturing of resources system, including establishing green manufacturing of resource system, studied the content to resource consumption of manufacturing system, choice of products for the environmental materials, content can optimal utilization of resources, technology, and the product life cycle and the life cycle of the logistics and energy management and control.

(3) Clean production process: is the use of advanced manufacturing technology (including green manufacturing technology) and green manufacturing process equipment and raw materials and equipment will be materialized and output in the form of product process, and implements comprehensive control for the whole production process, make the consumption of raw materials, discharge waste, energy consumption, health and safety risks and reduce the damage to the ecological to a minimum.

(4) The Product use and service (the right to the use of implement Product service-oriented manufacturing): set up Product service system, Product service system (Product service system of PSS) is the integration of products and services, users buy Product functionality or as a result, the target aimed at Product whole life cycle, by increasing the intangible service to tangible products, so as to achieve win-win of economy and the environment. 
(5) The green recycling: after the product is used by the user is entered the stage of recycling waste products recycling can not only realize renewable resources, and can reduce a lot of waste to the destruction of the environment and the harm to human health. Recycling process can be divided into reuse, remanufacturing, recycling three levels,

(6) Product reuse and remanufacturing: green remanufacturing is to scrap the product after disassembly, cleaning, inspection, renovation, repair and assembly again after the return to or close to the new product performance standards of a method of reusing resources. Green remanufacturing embodies the good environment, is to meet the requirements of sustainable development mode of production.

According to the time and position, the green remanufacturing can be divided into four stages: stage of remanufacturing design (refers to in the process of new product design for of remanufacturing for product design, distribution, to ensure that the product has good capability of remanufacturing), discarded product phase (which will waste recycling product to remanufacturing engineering phase), remanufacturing production phase (refers to remanufacturing process generated waste products remanufacturing product phase), remanufacturing product use phase (refer to the remanufacturing product sales, use and scrap stage).

\section{Conclusion}

The concept of green manufacturing system takes a comprehensive consideration for optimizing the utilization of resources and depressing the environmental impacts caused by the modern manufacturing system. With the increasing development of the green manufacturing theory and technology, the understanding on the green manufacturing system is dramatically changing. It is significant for the engineering application to correctly understand the concept and connotation of the green manufacturing system, as well as find out its compositions and operational natures.

\section{Acknowledgements}

Thanks for the funds supported by the Initial Research Fund of National Education Ministry for Abroad Scholars, P. R. China (No. 20151098) and the Open Fund of the Key Laboratory for Metallurgical Equipment and Control of Ministry of Education at Wuhan University of Science and Technology (2013A14).

\section{References}

[1] Fei Liu, Zhang Hua, Xiao-hui Chen. Integration characteristics of green manufacturing and green integrated manufacturing system $[\mathrm{J}]$. Journal of computer integrated manufacturing system, 1999 (4) $9 \sim 13$

[2] Guang-fu Liu, et al. Green design and green manufacturing [M]. Beijing: mechanical industry publishing house, 1999

[3] Fei Liu, Hua-jun Cao, Hua Zhang, et al. The green manufacturing theory and technology [M]. Beijing: science press, 2005.

[4] Ji-liang Zheng. Theory of green manufacturing systemic i n denigration [M]. Yunnan People's Press, 2009

[5] Fei Liu, et al. manufacturing systems engineering [M]. Beijing: National Defense Industry Press, 2002.

[6] Long-tai Wang, et al. manufacturing systemic engineering [M]. Beijing: Mechanical Industry Press, 2008.

[7] Cong-bo Li, Fei Liu, Hua-jun Cao. Green manufacturing operation mode and its implementation 
method [M]. Beijing: Science Press, 2011.

[8] Fei Liu, Cong-bo Li. Green Manufacturing Technology Connotation and System Framework Based on Product Life Cycle [J]. Journal of Mechanical Engineering. 2009(12):115 120

[9] De-cai Tang, On the Developmental Path of Chinese Manufacturing Industry Based on Resource Restraint [J]. Jiangsu Social Sciences. 2010(4):51 58

[10]Xiao-ru Chen, Xiang Li, Green Manufacturing of Auto Parts Based on Life Cycle Assessment [J]. Environmental Engineering. 2015(4):116 120

[11] Yan Guo, Hong-chao Liu. Review of Key Product Life Cycle Assessment [J].Computer Integrated Manufacturing Systems. 2014(5):42 46 